\title{
LEEUWEN, Richard van. Narratives of Kingship in Eurasian Empires, 1300-1800. Leiden: Brill, 2017.
}

\author{
Annie Venson Bogoni ${ }^{1}$
}

Narratives of Kingship in Eurasian Empires, 1300-1800 é o décimo primeiro volume de uma série de livros em contínua produção, Rulers \& Elites, organizada por Jeroen Duindam. A série se propõe a analisar o poder dos governantes e das elites de períodos e espaços diferentes a partir de aspectos culturais, literários, econômicos, entre outros. No caso da obra selecionada, a concepção e a legitimação de uma realeza diretamente relacionada ao poder, sejam de um rei, sultão ou califa, podem ser encontradas em narrativas literárias como espelho-depríncipes e histórias de aventura.

O autor de Narratives..., Richard Van Leeuwen, é professor na Universidade de Amsterdã e atua na área de Estudos Islâmicos. Suas pesquisas são majoritariamente sobre história do Oriente Médio, a literatura árabe e o islã no mundo moderno. Algumas de suas publicações são Waqfs and Urban Structures: The Case of Ottoman Damascus (1999) e The Thousand and One Nights: Space, Travel and Transformation (2007).

${ }^{1}$ Graduada no curso de História (Licenciatura e Bacharelado) da Universidade Federal do Paraná. Mestranda em História pela mesma instituição. 
Em sua Introdução, Leeuwen reconhece as dificuldades impostas pelo tema. As fontes selecionadas são histórias que sobrevivem ao tempo sofrendo algumas mudanças conforme o contexto perpassado. Um exemplo recorrente é a compilação de histórias de As Mil e Uma Noites, cujo título aparece por volta do século XII, mas alguns dos contos são de séculos anteriores e a obra completa permanece até a atualidade como uma grande referência literária. A sobrevivência destas narrativas e de seus temas permanece, também, devido às traduções e adaptações. Várias histórias criadas na Ásia, por exemplo, foram traduzidas para o árabe e turco pelos mamelucos e otomanos, permitindo que elas se difundissem por um grande espaço geográfico. ${ }^{2}$

As adaptações refletem os gostos e mentalidades de diversos períodos. O espaço e o período compreendidos pelas fontes, portanto, são demasiado vastos. Não foi possível aprofundar cada contexto de origem e de mudança das narrativas selecionadas separadamente. Mas o objetivo de Narratives... é outro: encontrar possíveis paralelos discursivos sobre poder e reinado em textos narrativos de impérios euroasiáticos entre 1300 e 1800 . De acordo com Leeuwen, a literatura era um meio importante para a compreensão e divulgação dos símbolos de poder. Além disso, traços de tradições orais são encontradas mescladas com

${ }^{2}$ Um exemplo seria o trabalho de Mamede Mustafa Jarouche, na tradução direta do árabe para o português da obra Livro das Mil e Uma Noites, publicada no Brasil em 4 volumes. JAROUCHE, Mamede Mustafa. O Livro das Mil e Uma Noites: volume I - ramo sírio. v. 1. São Paulo: Editora Globo, 2005. 
tradições escritas, significando um encontro entre o imaginário popular e o aristocrático.

A obra é dividida em seis capítulos, cada um tratando de um tema específico utilizando entre duas e seis histórias, sendo eles: os papéis do rei, dos vizires e das concubinas na trama; deuses e demônios em contato com o rei e sua influência na legitimação do governante; percepção divina e harmonia cósmica; a relação e diferenciação entre o cavaleiro e o rei; o amor e o poder soberano; e, por último, conselhos e críticas (desejados ou não) feitas ao governo. Para situar o leitor, o autor apresenta uma sinopse do conto seguida de uma análise aprofundada do mesmo. Devido aos limites instituídos pela quantidade de fontes e pelo tamanho da produção historiográfica, muitos detalhes do roteiro são explicados brevemente em meio à análise das obras.

A organização do texto é bem estruturada e clara, como descrevemos acima, cumprindo objetivamente o que é proposto no título e na introdução. Apesar de as sinopses serem extremamente breves - ponto que o próprio autor reconhece - alguns detalhes da narrativa são abordados conforme o tema, como a descrição de uma personagem ou uma cena específica que são determinantes para o argumento construído por Richard van Leeuwen. Estas amostras das histórias, porém, incitam o leitor a procurá-las e lê-las na íntegra. Os temas de cada capítulo se relacionam com as fontes e temas anteriores, criando uma rede de ligações entre os aspectos comuns às várias narrativas. 
O primeiro capítulo, Kings, Viziers, Concubines, traz quatro narrativas cujos pontos comuns incluem o governante como a personificação dos valores do reino, o vizir como o sábio conselheiro a ser seguido, e a concubina real que traz o desequilíbrio do reino. Os contos abordados são Seven Viziers ${ }^{3}$ e algumas de suas variações como Jali'ad of Hind and His Vizier Shimas, ambas de origem persa em sua versão de As Mil e Uma Noites, King Wu's Expedition Against Zhou e Proclaiming Harmony, ambas de origem chinesa. As versões das duas primeiras histórias utilizadas pertencem ao século XVIII, enquanto as chinesas datam do século XIV.

As narrativas persas possuem um formato comum, em que os desejos carnais e a influência das mulheres no governante trazem a ruína do império, restando ao sábio vizir redirecionar a impulsividade do líder imperial. Portanto, o posicionamento das personagens é bem claro: o rei aparece como representante do reino, às vezes cedendo às paixões; o papel do vizir é manter a tradição e a sabedoria por meio do aconselhamento; e a mulher causa a desordem, a enganação, as emoções irracionais. Estas características se mantêm, mesmo atravessando limites culturais e temporais. $\mathrm{O}$ perigo atribuído às paixões e o papel sábio dos ministros também aparece nos contos chineses, porém de forma mais simi-

${ }^{3}$ Este título se refere a uma gama de traduções e adaptações, alguns exemplos sendo $O$ Livro de Sinbad, na versão árabe, e The Seven Sages of Rome, como é chamado em vários outros idiomas. 
lar a um espelho-de-príncipe. A ficção não é tão presente quanto nas outras fontes: a história das dinastias é o principal elemento do roteiro, apresentando personagens e acontecimentos históricos.

Analisando o discurso de poder nestas fontes, Richard van Leeuwen destaca alguns pontos comuns. Em todas as narrativas, há uma ameaça de descontinuação da dinastia, seja pela falta de um príncipe ou pelo comportamento inadequado de um rei, obrigando a formação de novos princípios para o governo que visam o restabelecimento do império. Para isto, o rei deve ser iniciado na sabedoria e conhecimento acumulados na tradição humana, pois ele não apenas deve seguir seus princípios como deve personificá-los (LEEUWEN, 2017: 24).

No segundo capítulo, é abordada a relação entre a autoridade do governante e do vizir e a aparição de forças sobrenaturais na forma de deuses, demônios e espíritos, aparecendo como parte da iniciação da personagem. Para esta análise, foram utilizados contos sobre os reinantes Vikramaditya, Harun Al-Rashid e Wu, protagonistas semi-históricos. Os três ascendem ao poder de forma quase inevitável, como se forçados a assumir este papel. $\mathrm{O}$ autor afirma que de certa forma "eles são antiheróis, que atingiram sua posição apesar de si mesmos, como se obrigados por forças irresistíveis a assumir suas responsabilidades" (LEEUWEN, 2017: 76) $)^{4}$.

${ }^{4}$ Tradução de minha autoria. 
Eles estão diretamente relacionados às forças sobrenaturais (encantamentos, objetos mágicos, demônios) e sua autoridade é concebida pelo divino. No entanto, é uma autoridade a ser conquistada de acordo com a disposição de ajudar a população. É interessante notar como os elementos sobrenaturais se alteram conforme o período e região, como a cosmologia e mitologia hindu na versão bengalesa e referências a práticas islâmicas em versões persas posteriores. O conhecimento esotérico e o esclarecimento divino também aparecem como determinantes para a formação do protagonista. Esta transformação possibilita perceber a influência do contexto do autor ou tradutor na obra sobre a qual ele trabalha.

Histórias como The Queen of Serpents (introduzida em As Mil e Uma Noites no século XVIII), The Sorcerer's Revolt (um romance compilado pelo chinês Feng Menglong no século XVII) e Manuscrit Trouvé à Saragosse (escrito por Jean Potocki no século XIX) apresentam a iniciação do príncipe ou vizir ao conhecimento esotérico, visando a atingir o meio termo entre crença e superstição, entre morais extremas e entre os interesses humanos e divinos. A autoridade e legitimidade do governante, portanto, são situadas de acordo com suas relações com a religião e as forças sobrenaturais de forma bem ampla. Sua autoridade se naturaliza e harmoniza com forças cósmicas, denotando a importância do equilíbrio nas relações e atribuindo o nome do terceiro capítulo, Divine Insights, Cosmic Harmony. 
Além de reis e ministros, outra figura é destacada por Leeuwen: o cavaleiro. O autor comenta: "Há dois temas que parecem estar presentes em literaturas pelo mundo inteiro: amor e guerra" (LEEUWEN, 2017: 109). No quarto capítulo, foram selecionados seis romances cavalheirescos variando geográfica e temporalmente, de tradições europeia, persa/urdu, chinesa, árabe, malaia e turca. Neles, a ascensão ao poder se dá não por um sucessor sanguíneo, mas por um guerreiro que passa por uma iniciação para se tornar o soberano. Os cavaleiros abordados são Tirante o Branco, Amir Hamza, Yue Fei, Hang Tuah, Al-Zahir Baybars e Sayyd Battal. Um conto apresenta uma inclinação para o aspecto biográfico, o Romance of Baybars, cujo protagonista é estrangeiro, forasteiro naquela sociedade e governo.

Richard van Leeuwen aborda Ron Sela, que pesquisou biografias com aspecto fictício de Tamerlão que apareceram no século XVIII em turco e persa. Sela compara estas biografías com a de Baybars, e Leeuwen concorda com a ideia de que ambas as narrativas encaixam na categoria literária semipopular, combinando elementos populares com discursos aristocráticos de poder. Os valores morais defendidos pela comunidade são determinantes para a legitimação destas duas figuras, tornando-as modelos de um líder ideal antes de colocá-las no poder. Estes valores apresentam uma conexão entre a cultura popular e a elitizada.

A figura da mulher muda nestas últimas narrativas: seu papel ainda é determinante, mas desta vez de forma positiva. Porém, ela nunca 
ocupa um lugar de poder, sua posição é de subordinação à das outras personagens nas narrativas abordadas. Leeuwen descreve os contos como misóginos, mesmo para o contexto em que se encontravam. Em Tirant lo Blanc e The Book of Amir Hamza o caso é mais complexo: a figura feminina está envolvida com a estrutura de poder e autoridade, atuando como referencial de virtude e lealdade. Há, portanto, um paradoxo, em que por um lado sua posição é marginal, mas por outro possui um poder simbólico forte. Ela atua como ruptura e ao mesmo tempo como continuidade.

As relações entre os gêneros são foco dos romances de amor, aprofundados no quinto capítulo do livro. Este é dividido em duas partes, uma analisando um agrupamento de uma rede de histórias de amor árabe-persa e hindu, e outra um agrupamento de romances de cavalaria que se tornaram contos de amor na Europa. Nos contos, percebe-se a conexão direta entre a realeza e o amor na busca pela pessoa amada na forma de uma aventura. Um padrão é identificado nas primeiras cinco fontes, pertencentes às tradições árabe, persa, hindu, indiana, e nas fontes europeias.

O amor fornece não só um enredo dramático, mas também o paradoxo feminino tratado anteriormente: a interrupção da dinastia devido à paixão e a continuidade da mesma pela sexualidade. Entre a ruptura e a continuidade, há o período de busca e aventura por parte do príncipe. A ameaça de ruptura surge com o fato de o amor e de a sexualidade 
possivelmente quebrarem regras sociais e instituições. Desta forma, este sentimento se manifesta como destino, afetando não só as duas personagens envolvidas, mas também a comunidade inteira por meio de suas ações.

No sexto e último capítulo, Richard van Leeuwen apresenta narrativas ficcionais e semificcionais que criticam o usufruto do poder pelo governante. Seus autores eram indivíduos que voluntariamente tomaram a posição de vizir e tentaram corrigir o rei, mesmo que seu aconselhamento não fosse requisitado e muitas vezes oprimido. Eles são produzidos em períodos prósperos governados por poderes absolutos, podendo ser considerados "absolutismos esclarecidos" (LEEUWEN, 2017: 200), que incluem as dinastias Ming e Qing, os impérios Mogol e Otomano e as casas reais da Espanha, França, Inglaterra e Áustria.

Diferente das narrativas anteriores que visam a facilitar o discurso de poder, estas questionam sua efetividade e problematizam a relação entre comunidade e governante. A contestação se dá diretamente ao líder por meio da crítica ou pela recomendação de alternativas que diminuam seu poder absoluto. Obras do Oriente Médio e da Ásia contribuíram para as produções no Ocidente nos séculos XVIII e XIX, visto que o contato entre estes se intensificou, criando novas e mais complexas formas de visão de mundo.

Concluindo a obra, Leeuwen destaca como as narrativas funcionam sempre dentro da estrutura de poder e autoridade, dialogando entre 
a visão da corte e a visão popular. O hibridismo que permite esta conexão insere na imaginação coletiva valores que consolidam as estruturas de poder. A história serve como repositório de identidades, de valores culturais e morais, geralmente projetadas sobre uma figura específica, e como fonte de legitimação (LEEUWEN, 2017: 255). A religião também aparece com papel semelhante, fornecendo valores e um sentimento de experiência comum, junto da história. O que permite a permanência de uma narrativa através do tempo e do espaço, porém, é seu impacto e sua capacidade de se reinventar como fenômeno cultural e literário.

Narratives of Kingship in Eurasian Empires é uma ótima leitura tanto para interessados em história quanto em literatura, estabelecendo um rico diálogo entre as duas áreas. Como tratado nesta resenha, a quantidade de fontes narrativas é grande, fornecendo um panorama geográfico e temporal vasto para entender as manifestações literárias sobre discursos de poder entre 1300 e 1800.

Recebido em: 29/11/2018

Aceito em: 13/09/2019 